\title{
Cultural aspect of toast as a small speech genre in the paradigm of modern linguistic science
}

\author{
Svetlana Kruglova $^{1 *}$, Irina Zubkova ${ }^{1}$, Irina Kuzminova $^{1}$, and Irina Zhivotkova ${ }^{1}$ \\ ${ }^{1}$ Don State Technical University, Gagarina str, 1a, Rostov-on-Don, 344000, Russia
}

\begin{abstract}
Toasts logically fit into the modern cultural space, which includes a certain layer of it - folklore. Folklore studies as a field of artistic creativity actively exists in a variety of forms and forms in modern reality. This phenomenon is dynamic, actively developing, rapidly transforming; it interacts in the humanities with such capacious concepts as post-folklore, subculture; it reflects the qualitative changes in social and everyday life that are characteristic of our era. Conceptually, the subject field of urban folklore is relatively clear and to some extent, we can say, mastered, despite its specificity and versatility.
\end{abstract}

\section{Introduction}

Toasts are a certain form of folklore creativity and along with greetings, jokes, anecdotes, drinking songs, congratulations, etc.are in the general field of various semantic and semantic genres of urban folklore. In the form of a genre, toast was formed a very long time ago, recently it has been developing quite quickly, as it has a stable position in almost any festive or non-festive feast. The appearance of various collections of toasts, parables, toastsjokes, holiday scenarios, Internet products of all kinds, etc. promotes the functioning and wide dissemination of folklore works. We believe that the production of printed format, which has a certain template, "to order" to a certain extent makes this material "depersonalized", devalues it, but, if you look at it from the other side, gives you the opportunity to freely interpret it, transform, rethink, make your own versions, and this corresponds to the genre attributes of folklore.

Even in our time, certain components of urban folklore require a more comprehensive, thorough, serious understanding and description by linguistics. All this has to do with toasts in full. Toasts have been the subject of research in cognitive science and linguistics relatively recently.

Nowadays the collective's various feasts cannot be imagined without the use of toasts, which is why we think that the toast in the system of modern values associated with linguistic and cultural specifics has gained a certain position, as well as a genre of urban folklore is interesting linguistically as a research scientific object. This is the relevance and expediency of the study of toast in the form of a special speech genre within the framework of the anthropocentric paradigm.

Studies have shown that:

\footnotetext{
* Corresponding author: svetazh@inbox.ru
} 
1. On a more detailed examination of urban folklore's some objects, certain ones require a linguistic description and a particularly close multi-faceted understanding. This also applies to toasts, which were not studied in Russian linguistics and cognitive science until recently.

2. One of the main obstacles to the study of toasts is their dense correlation and semantic relationship with such definitions as "drinking", "feast", at a time when aesthetic and ethical-moral criteria did not allow them to be studied.

3. The transformation of the "culture of drinking", as well as changes in people's consciousness concerning aesthetic tastes, moral norms, ethical norms in a democratizing direction, the turn of cultural and social orientations, the large increase and spread of meals in the collective helped to add traditional folk forms of folklore to the artistic and value circle.

The purpose of this study is to describe toast as a small speech genre linguoculturologically and in the form of a certain variation of the precedent text in the cultural space.

\section{Materials and method}

The material of the research are the well-known works of Soviet and foreign linguists in the field of intercultural communication, linguoculturology, the theory of speech acts and the theory of speech genres in the contactological field.

During the analysis of the material, the following methods were used: observation, descriptive, semantic analysis, component analysis, statistical and comparative analysis, as well as the interpretation of the studied linguistic sources.

\section{Results}

A toast is an unusual text that was pronounced in the ceremony of the feast. The toast text should be considered as a precedent, it exists in written and oral form. The oral form, for obvious reasons, is considered basic and primary. The written form is qualified as conditional, secondary, since on the Internet, in various collections, there are all sorts of written fixations of toasts.

The practical significance of the results obtained: the results of the work can be used in the study of special courses in pragmalinguistics, cognitology, contactology, linguoculturology, which will further expand their informativeness and aspectuality; as well as in teaching various disciplines of a philological nature, including speech communication as a visual material on speech culture, stylistics. Also, the research material can be used in writing special texts-publications that record the current position of the genre originality of urban folklore.

\section{Discussion}

In genre form, toasts have a huge variety and a close relationship with the folklore "subculture of free time". This subculture can be conditionally divided into two unifying complexes of ritual urban modern folklore: in the sphere of home life - these are birthdays, send-offs to the army, christenings, weddings, anniversaries, "hen parties", "stag parties", funerals, and so on; which is the repertoire of home feasts of our time, including in the family circle; in the sphere of public life, these are themed traditional holidays, proms, corporate parties, rites of "initiation" (for example, in warriors, in students, etc.), alumni meetings, and many others. 
In modern society, it is almost impossible to imagine all these collective meals without toasts, which is why we believe that toast has taken a certain place in the system of values of our time, which are associated with linguistic and cultural specifics, and in the form of a genre of urban modern folklore, it is linguistically attractive as an object of scientific research.

From the point of view of literary studies, the name of this speech genre is borrowed from the English language and means "toasted bread". In the English tradition, a glass and a slice of toasted bread were placed in front of the person who spoke with a small table statement [1]. So, people living in the British Isles, before drinking wine, dipped a toasted slice of bread on the fire, so that the bread aroma permeated the drink. After a while, this tradition was forgotten, but instead a new one appeared: before drinking wine, you had to say a toast speech.

It is impossible to ignore another version of the origin of the word "toast", which today in the linguistic environment causes some controversy. So, according to a number of philologists, the word toast is of Turkic origin. According to etymology, in the Spiritual Letter of Ivan Kalita (1340) and the Russian letter (1356), the word "dostakan" is found, meaning the name of the Turkic wooden dishes such as bowls-tostakan. Presumably, the word toast originated from him. A toast was made when a TOSTakan (later a glass) or other vessel was raised. Toast and glass, as you can see, are united by the word tostakan. In our time, we note that the word tostagan is widely used in Kazakhstan - it is a wooden dish that resembles something in shape between a bowl and a bowl, most often intended for serving kumis on the table. This version is not widely distributed, but, in our opinion, it has the right to exist, since such a justification sounds quite logical [2].

The study of various lexical interpretations of the word toast, which are quite common in oral-speech discourse, has shown that there are still differences in linguistics in the question of whether toast is related to an act of communication, or to an act of speech, or to the genre of speech, despite the fact that these definitions have common components of semantics. The concept of A. Vezhbitskaya, in our opinion, is the most acceptable and relevant. According to this concept, it is advisable to combine the definition of the "speech genre" proposed by M. Bakhtin with the theory of speech acts. In the opinion of A. The concept of the word "genre" is not as misleading as the concept of the word "act", since the word "act" has a representation as a one-time, short statement. V.V. Dementiev believes that the speech genre should be considered as a structural and systemic phenomenon, which is a multifunctional set of a large number of speech acts, first selected, and then connected for certain reasons of some expediency and related not directly to reality, but through the genre of speech as a whole.

Of all the definitions of toast presented in the study, the authors of this article chose the definition, the structure of which contains the main categorical semantic feature, and specifically the concept of genre in T. Matveeva: toast is a small genre of everyday eloquence: toast, zazdravnaya table speech [3].

Table genres of speech are considered a special group of genres that regularly function at a collective meal and are considered its mandatory and quite important attribute. Almost every text of the toast contains certain components: traditional preparation, speech formulas, epistolary cliches, they are inherent in the author's individual beginning, since toasts are characterized by improvisation, variation, transformation. Thus, toast as a genre has the properties of both variability and standardness.

In our understanding, a toast is a statement with special characteristics and stereotypical elements that reflects a particular area of human activity (for example, the culture of feasting / drinking). The toast has three obligatory components: compositional structure, style, thematic content, which, in turn, are inseparable, contain their own specifics and equally proceed from the specifics of any sphere of communication [1]. In other words, 
toast as the primary genre of speech has grammatical, phraseological and lexical components, as well as other means of language. Toast speech is an illocutionary act that implements the author's intention and implies a certain "drama" of the participants ' behavior in different communication situations.

The small speech genre of toast in oral-speech discourse has certain differential features, in addition to integral ones. One of these signs is associated with the fact that toast speech can be attributed unambiguously to contactology, its feature is the most friendly expression of attitude to the interlocutor, the establishment of exclusively positive contacts that help to reduce the distance of space between people participating in the feast.

The toast reflects a deep philosophical understanding of the" nature of the word" as a material sign, and its key message is connected with this: everything that is said during the toast must come true, materialize, and this is a special harmony of the thematic and content side of the analyzed small genre of speech. In many cultures, it is absolutely no accident that toasts are positioned with "certain amulets", which are associated with verbal energy, its power; with a certain "God-pleasing beginning". It is believed that in order for the toast made by the speaker to come true, "higher forces" are attached to the statement: "May God help you!", "God bless you", "May God bless you!", "May the guardian angel guide you!", etc., etc.

According to the typology of T. V. Shmeleva, toast is a label-speech genre, the communicative purpose of which is to emphasize the importance of the event, to express good wishes to the addressee. Naturally, the composition and content part, the idea, and the pronouncing rhetoric of the toast correspond to the speech etiquette norms and ritual traditions. However, we believe that such a concept to some extent thus narrows the number of ritual genres of speech, since the hidden goals of the participants in communication remain outside the framework of linguistic research, and only the nearest ones are taken into account.

In fact, there are a large number of auxiliary goals in order to achieve successful communication. So E. F. Tarasova believes that it is necessary to attract the attention of the interlocutor, directly establish contact with him, and then start a conversation. And this is an important aspect of communication: it is on how you cope with the task of establishing contact, attracting the attention of the interlocutor, that the success of a particular speech act will depend [3]. After establishing contact and attracting attention, the communicant, for example, can make certain efforts to maintain, create or destroy a trusting atmosphere to the information source, as well as to the transmitted information, in order to arouse interest in what is expressed (in order to create a cognitive need) [3]. The goals described above take place in the toast speech genre and it would be impractical to ignore them.

We believe that the toast background of the context initially assumes the communication strategies included in it, which are associated with the category of politeness, which acts as a kind of contact function from the point of view of speech etiquette. We agree with Kiseleva L. A., who suggests that "impoliteness / politeness" is considered a modification of "contact", i.e. a more general category. And indeed, toast, like other small speech genres, such as gratitude, congratulations, compliments, is an indicator of politeness, because of which the contact-setting function is implemented. As the researcher O. S. Akhmanova notes, the contact-setting function is clearly manifested when the communicator does not have the desire to immediately transmit any information to the recipient, but only wants to give a certain naturalness to a joint location, prepare the addressee for the correct perception of the message, pay attention to himself, etc.

The interaction of contacts, which is aimed at a friendly establishment and which leads the interlocutors to a psychological rapprochement, is expressed in a toast speech in the form of addresses in the initial position: "Friends!", "Dear newlyweds!", "Our dear 
guests!", "Dear colleagues!", indicating the family ties or the name of the addressee of the speech: "Beloved brother!", "Dear Maxim!", etc.

Researcher G. G. Pocheptsov refers such speech turns to the "zero phase of communication". He highlights the following: the task of metocommunication, which is solved at a specific phase of the conversation (in addition to the formation of a speech contact), is quite often to establish the source of the expression / author. Therefore, with the help of the phatic, or contact-setting function, an act of speech occurs in the toast, and any parameters that relate to the relationship and personality of the interlocutors are clarified.

In the aspect of speech etiquette, the regulatory and social function of toast speech is no less important. The content of this function is determined by the dependence of the choice of the toast of the communicants on their social role, education, marital status, status, situation, profession, gender, place, age, social class, race, nationality, and so on. It is known that these factors have a twofold effect on the behavior of the interlocutors. First, they "determine the language repertoire of communicants"; second, they "determine the nature of their relationships". For example, a toast with various wishes at a wedding, addressed to one of the guests, will sound extremely inappropriate; comic toasts will be inappropriate during an official reception; it is not recommended to say "you" to an elderly person, as well as to wish him fun.

Different toasts are characterized by variation, transformation, individuality, improvisation, authorship, despite the fact that almost all toast speeches have epistolary cliched phrases, contain a traditional blank, different speech formulas.

A certain act of communication, a toast, belongs to the sphere of interpersonal relations. It is based on the idea of the importance of interaction between two parties: "transmitting" and "receiving" (addressee and addressee). Thus, a toast is a speech act of people: the speaker of the text and the group of persons / person to whom it is directed.

The speaker evaluates the situation of speech, chooses the means of expression and determines the questions of action. T. G. Vinokur notes that there is a "dialogic layer" in the assessment of the addressee, which should be guided by the addressee. During the utterance of an expression, depending on the implemented / expected reaction of the perceiver of speech, the listed structural components of the impact of the utterance can be modified.

The following remark of researcher N. D. Arutyunova, in our opinion, is significant. The addressee enters the communication process not as a global personality, in which all its components are merged together, but as a "parameterized" personality, which reveals in the speech act only one of its psychological aspects or social functions, in connection with which his utterance should be understood. In a large number of cases, there is no doubt that the toast that was uttered contributes to obtaining certain information about the speaker, for example, helps to learn his social role (husband, parent, girlfriend, brother); status (boss, colleague, junior or senior family member); psychological characteristics (values, feelings, mood, emotions).

E. V. Klyuev says that the addressee's position in the theory of speech genres occupies one of the key positions. In the structure of the act of communication, by now there is already a common opinion about the view of the listener, which is one of the key "components", not because it is obvious that the exchange of information, the communication act cannot take place without the addressee, but because not only the producer is involved in the structuring of the speech situation, but also the listener is involved in its structuring.

Linguistics in the modern world recognizes that the speaker has a key role, which implies active actions from the performer. It is noteworthy that the recipient is an actor not during the act of communication, but already at the time of the alleged beginning of interaction. M. M. Bakhtin draws our attention to the fact that in the process of speech itself, it is constantly necessary to take into account the "apperceptive" background of 
understanding by the listener, which determines the response active perception of the expression by the speaker.

Absolutely any genre of speech can be designed for a specific model of the recipient. The toast, of course, is addressed to a certain person, the hero of the celebration, for which people gathered at one table. But, despite this, the speech is also heard by other guests who have gathered to eat. In order to characterize the roles of communicants, T. B. Carlson and G. G. Clark introduced the definition of "audience sketch". According to this concept, communicants are divided into the addressee and the participants of the speech act. This is especially important in the category of toasts "for all occasions": "for happiness", "for love"," for spring in the soul"," for friendship"," for a dream"," for health", etc. Here the initiator of the communication act sets only the goal, and the addressee implements its plan. Thus, in toast, the interaction of the speech act is subordinated to the principles used in purposeful activity. We believe that the age and gender characteristics of the participants in the conversation should be taken into account as classification indicators that affect the process of communication in the space of the act of communication, since the personality of the communicant, of course, has specific linguistic and psychological characteristics [1].

Table 1. Toast as a unit of a small etiquette-speech genre.

\begin{tabular}{|c|c|c|c|}
\hline Integral features & & Differential signs & \\
Clear composition (language & & Contact & \\
preparation, cliches, certain speech & \multirow{2}{*}{$40 \%$} & $\begin{array}{c}\text { Philosophical understanding of the } \\
\text { formulas) }\end{array}$ & $60 \%$ \\
$\begin{array}{c}\text { Speech style } \\
\text { Thematic content }\end{array}$ & & $\begin{array}{c}\text { Etiquette norms } \\
\text { Following to traditions }\end{array}$ & \\
\hline
\end{tabular}

\section{Conclusion}

Consideration of the theory of the conceptual nature of the small speech genre - toast-in oral discourse shows that, undoubtedly, toast is a label-speech genre. In addition, the analysis of toast speech in the field of methodological theoretical basic definitions has shown that the nature of toast linguistics manifests almost all the necessary known aggregates of the process of a communicative act and is very logically included in the paradigm of speech communication according to various parameters that are united by the situation, composition and topic of speech communication.

In the modern language of the city toasts, of course, have a direct connection with the subcultural manifestation of the direction, since they as well as in general urban folklore, are consistent with the age, social, professional and other stratification of society.

The study of toasts showed that they are an independent genre of speech, functioning on the basis of clearly defined object-situational relations, although they certainly correlate with such close related concepts as table speech, wishes, praise, table conversation, congratulations, compliments, "letters of happiness".

\section{References}

1. N.M. Loktionova, S.A. Kruglova, O.A. Drozdova, In Proceedings of the International Scientific and Practical Conference "Current Issues of Linguistics and Didactics: The Interdisciplinary Approach in Humanities and Social Sciences" (CILDIAH-2018), 50, (2018), https://doi.org/10.1051/shsconf/20185001019

2. http://encyclopaedia.bid/wikipedia/Toast 
3. E.M. Arkhipova, Scientific Thought of the Caucasus, 3, 151-155 (2010)

4. M.D. Vasilyeva, R.M. Vlasova, Yu.V. Nikolaeva, Yu.D.Potanina, Questions of Linguistics, 1, 155-160 (2015)

5. V.B. Gulida, Narodnaya Lingvistika, 5, 136-144 (2013), doi: 10.31857/SX0000392-4-1

6. S.D. Shelov, A.E. Tsumarev, Questions of Linguistics, 13, 138-144 (2015)

7. I.G. Ovchinnikova, T.V. Akhutina, Questions of Linguistics, 3, 131-140 (2016)

8. E.E. Baratashvili, Volgograd State Agricultural Academy, 2,160-163 (2011)

9. M.Ch. Kremshokalova, Izvestija Russian State Pedagogical University im. A.I. Herzena, 151, 89-96 (2012)

10. T.Ju. Sazonova, I.S. Borozdina, Voprosy Kognitivnoj Lingvistiki, 2 (023), 27-33 (2010)

11. E.G. Beyninson, Scientific Bulletin of YIM, Linguistics and Communication Problems, 4, 37-39 (2014)

12. D.L. Gajibalaeva, Scientific Thought of the Caucasus, 3, 78-83 (2018), doi: 10.18522/2072-0181-2018-94-2-78-83

13. N.I. Shikhkebirova, Bulletin of the Pyatigorsk State Linguistic University, 3, 42-45 (2011)

14. L.V. Balashova, XI Shmelev Readings, 6, 24-32 (2015)

15. M.A. Kormilicina, XI Shmelev Readings, 6, 139-147 (2015)

16. N.M. Loktionova, L.K. Alakhverdieva, O.A. Fomina, In Proceedings of the International Scientific and Practical Conference "Current Issues of Linguistics and Didactics: The Interdisciplinary Approach in Humanities and Social Sciences" (CILDIAH-2018), 50, (2018), https://doi.org/10.1051/shsconf/20185001004

17. N.M. Loktionova, I.A. Kuzminova, S.A. Kruglova, In Proceedings of the 7th International Scientific and Practical Conference "Current issues of linguistics and didactics: The interdisciplinary approach in humanities" (CILDIAH 2017), 50, (2017), https://doi.org/10.2991/cildiah-17.2017.26

18. N.M. Loktionova, O.A. Fomina, I.A. Kuzminova, Humanities, Social-Economic and Social Sciences, 5, (2013), doi: 10.23683/1995-0640-2018-4-74-81

19. N.M. Loktionova, I.A. Kuzminova, S.A. Kruglova, In Proceedings of the 7th International Scientific and Practical Conference "Current issues of linguistics and didactics: The interdisciplinary approach in humanities" (CILDIAH 2017), 97, (2017), https://doi.org/10.2991/cildiah-17.2017.26

20. N.M. Loktionova, O.A. Fomina, L.K. Alakhverdieva, In Proceedings of the 7th International Scientific and Practical Conference "Current issues of linguistics and didactics: The interdisciplinary approach in humanities" (CILDIAH 2017), 97, (2017), https://doi:10.2991/cildiah-17.2017.61 